\title{
PENINGKATAN KUALITAS CITRA SIDIK JARI DENGAN ALGORITMA MINUTIAE EXTRACTION DAN LEARNING VECTOR QUANTIZATION
}

\author{
Julius Santony ${ }^{1 *}$, Retno Devita ${ }^{2}$, Aulia Fitrul Hadi ${ }^{3}$, Ruri Hartika Zain ${ }^{4}$ \\ 1Program Studi Sistem Informasi, Universitas Putra Indonesia "YPTK" Padang, Indonesia \\ ${ }^{24}$ Program Studi Sistem Komputer, Universitas Putra Indonesia "YPTK" Padang, Indonesia \\ ${ }^{3}$ Program Studi Teknik Informatika, Universitas Putra Indonesia "YPTK" Padang, Indonesia \\ Jl. Raya Lubuk Begalung Padang \\ *Corresponding Author: juliussantony@yahoo.co.id
}

\begin{abstract}
ABSTRAK
Untuk mengindentifikasi seseorang dapat digunakan sistem pengenalan sidik jari. Masalah Kendala utama untuk pengenalan sidik jari seseorang adalah karena kualitas citranya rendah. Kualitas tersebut dipengaruhi karena jenis kulit yang kering, kotor, berminyak dan jenis alat scanner fingerprint yang digunakan. Untuk itu dilakukan peningkatan dengan tujuan memperbaiki citra sidik jari sebagai faktor utama penentu tingkat akurasi hasil pengenalan citra sidik jari. Supaya citra sidik jari yang tidak jelas lebih mudah diinterpretasi oleh manusia atau mesin, maka perlu peningkatan kualitas citra tersebut dengan cara memperjelas garis sidik jarinya. Penelitian ini bertujuan untuk peningkatan kualitas citra sidik jari dengan Algoritma Minutiae Extraction dan metode Learning Vector Quantization(LVQ) sebagai pengujian. Pengujian menggunakan 4 jenis data citra berdasarkan jumlahnya, jenis pertama sebanyak 25 data citra, jenis kedua sebanyak 50 data citra, jenis ketiga sebanyak 75 data citra dan jenis keempat sebanyak 100 data citra. Dari hasil pengujian didapat hasil terbaik dengan 75 data citra sidik jari, yaitu dengan akurasi 83.34\%.
\end{abstract}

Kata Kunci: Sidik Jari, Peningkatan, Citra, Algoritma Minutiae Extraction, Learning Vector Quantization

\begin{abstract}
Fingerprint recognition system aims to identify someone. The main obstacle in recognizing a person's fingerprints is that the image has a low quality. The quality is caused by the type of oily, dry, dirty skin and the type of fingerprint scanner used. For this reason, an increase was made with the aim of improving fingerprint images as the main factor determining the level of accuracy of fingerprint image recognition results. In order for fingerprint images to be easily interpreted by humans and machines, it is necessary to improve quality by clarifying the fingerprint line. This study aims to improve the quality of fingerprint images with the Minutiae Extraction algorithm and the Learning Vector Quantization (LVQ) method as a test. This test is carried out using 4 images as training in each class. The total number of classes in this test is 10 classes with each class consisting of 10 images. In testing 75 fingerprint image data obtained an accuracy rate of 83.34\%.
\end{abstract}

Keywords: Fingerprint, Improving, Image, Minutiae Extraction Algorithm, Learning Vector Quantization

\section{PENDAHULUAN}

Setiap manusia memiliki ciri sidik jari yang berbeda beda. Hal ini dapat dijadikan sebagai identitas diri setiap orang. Untuk mengetahui pola sidik jari seseorang, dapat dilakukan deteksi sidik jari dengan alat bantu teknologi komputer [1]. Teknologi ini dengan mudah dapat mengenali dan mengidentifikasi sidik jari seseorang, yang disebut dengan biometrik [2].

Adanya sistem deteksi citra sidik jari ini, disebabkan karena karakteristik atau pola dari sidik jari memiliki sifat permanen [3]. Sidik jari seseorang tidak berubah sepanjang hidupnya seiring dengan bertambahnya usia seseorang, kecuali perubahan yang disebabkan oleh kecelakaan dan penyakit [4].

Penelitian yang pernah dilakukan untuk mengenali sidik jari yaitu dengan Algoritma Garbor Filter yang dapat mengekstrak fitur citra sidik jari dengan nilai efisiensi rata-rata $82,95 \%$ dan $89,86 \%$ [5]. Kemudian penelitian pengenalan sidik jari dengan Metode Artificial Neural Networks (ANN). Hasil yang diperoleh, pola sidik jari dapat dikenal dengan tingkat akurasi 80\% [6].

Pada penelitian ini, pengenalan citra sidik jari dilakukan berdasarkan garis-garis yang terdapat pada sidik jari (minutiae), kendala yang sering dijumpai adalah hasil citra sidik jari yang diambil 
berkualitas rendah seperti citra sidik jari berminyak, citra sidik jari kering dan citra sidik jari kotor. Ketiga faktor ini menyebabkan garis terputus (ridge ending) dan dua garis yang bertemu di salah satu ujungnya (ridge bifurcation) menjadi tidak sempurna, saling terhubung dan putus-putus sehingga bisa mempengaruhi nilai minutiae [7].

Untuk mendapatkan nilai minutiae yang tepat maka citra sidik jari perlu ditingkatkan kualitasnya dengan menggunakan Algoritma minutiae extraction. Setelah didapat nilai minutiae maka dilakukan pengujian akurasi dengan menggunakan LVQ. LVQ dapat melakukan pemrosesan klasifikasi untuk menemukan sebuah model atau fungsi yang menjelaskan dan mencirikan konsep atau kelas data untuk kepentingan tertentu [8]. Dengan adanya proses klasifikasi pada LVQ ini, dapat menentukan tingkat akurasi dari pengenalan citra sidik jari.

\section{METODE}

Metodologi penelitian yang dilakukan, secara umum dapat dilihat pada kerangka kerja penelitian sesuai dengan gambar 1 berikut ini:

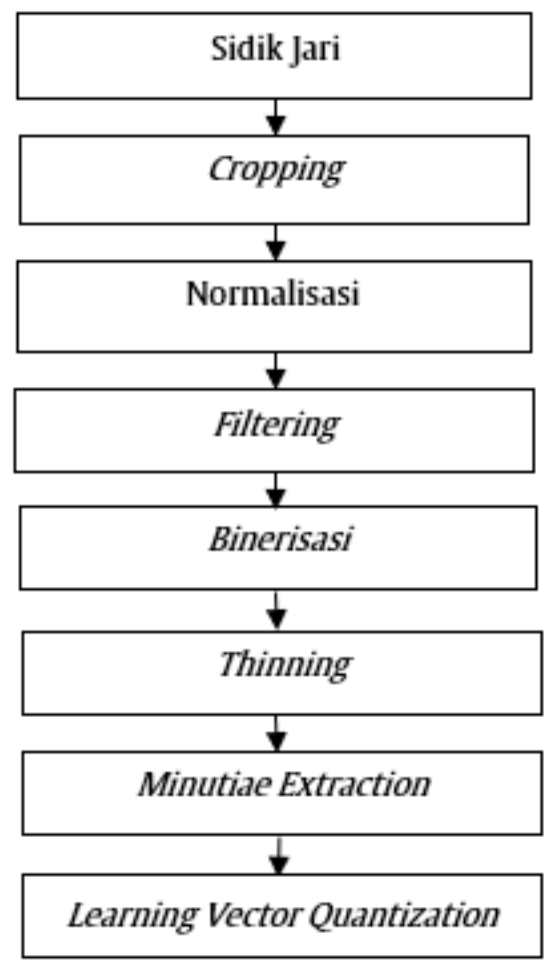

Gambar 1. Kerangka Kerja Penelitian

Berdasarkan kerangka kerja penelitian pada gambar 1, maka masing-masing langkahnya dapat diuraikan sebagai berikut:

\section{1) Sidik jari}

Objek yang digunakan pada pengujian ini adalah citra sidik jari. Citra sidik jari adalah hasil scan yang menggunakan mesin fingerprint HS-52 yang diproduksi oleh Silicon dengan mendapatkan ukuran citra piksel grayscale dalam format bitmap. Data diambil dari ibu jari 10 orang dengan 10 sampel per jari (100 citra sidik jari).

\section{2) Cropping}

Proses cropping dilakukan untuk menghilangkan bagian yang tidak diperlukan pada sebuah citra [9]. Pada penelitian ini, hasil dari proses scanning citra sidik jari langsung dilakukan cropping untuk dapat menghilangkan bagian citra yang tidak digunakan dengan mendapat ukuran 221x221 piksel grayscale dalam format bitmap. Tahapan-tahapan proses cropping dapat dilihat pada program berikut ini:

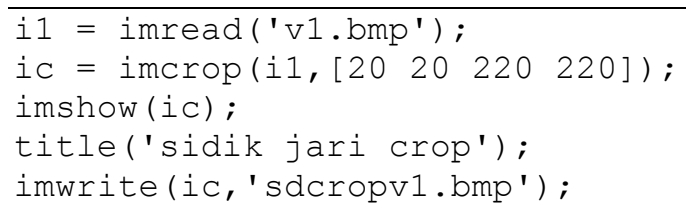

\section{Gambar 2. Program Cropping}

\section{3) Normalisasi}

Proses normalisasi dilakukan untuk menyeragamkan nilai intensitas citra sidik jari dengan cara menyesuaikan derajat keabuan [10]. Pada proses ini menggunakan histogram equalization untuk meratakan histogram agar derajat keabuan dari yang paling rendah (0) sampai dengan yang paling tinggi (255) mempunyai kemunculan yang rata dengan histogram equalization hasil citra sidik jari yang memiliki histogram yang tidak merata atau distribusi kumulatif yang banyak loncatan gradiasinya akan menjadi citra sidik jari yang lebih jelas karena derajat keabuannya tidak dominan nilai piksel gelap atau dominan nilai piksel terang. Oleh karena itu normalisasi citra sidik jari diperlukan untuk meningkatkan kontras antra ridge dan valley. Tahapan-tahapan proses normalisasi dapat dilihat pada program berikut ini:

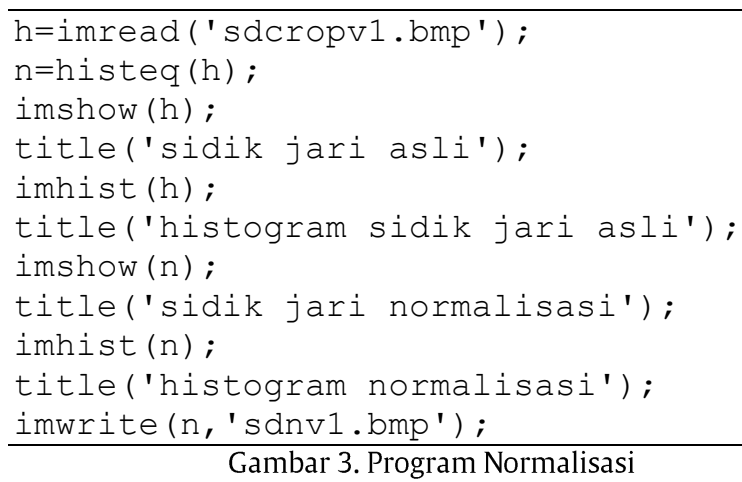




\section{4) Filtering}

Proses Filtering dilakukan dengan mensimulasikan karateristik system visual manusia dalam mengisolasi frekuensi dan orientasi tertentu dari citra. Proses filter ini diterapkan ukuran gabor filter sebesar $32 \times 32$, wavelength atau panjang gelombang sinusoid akan mempengaruhi lebar dari ciri yang akan ditampilkan ditetapkan nilainya sebesar 10 dan sigma dari gaussian sebesar 4. Berikut program filtering:

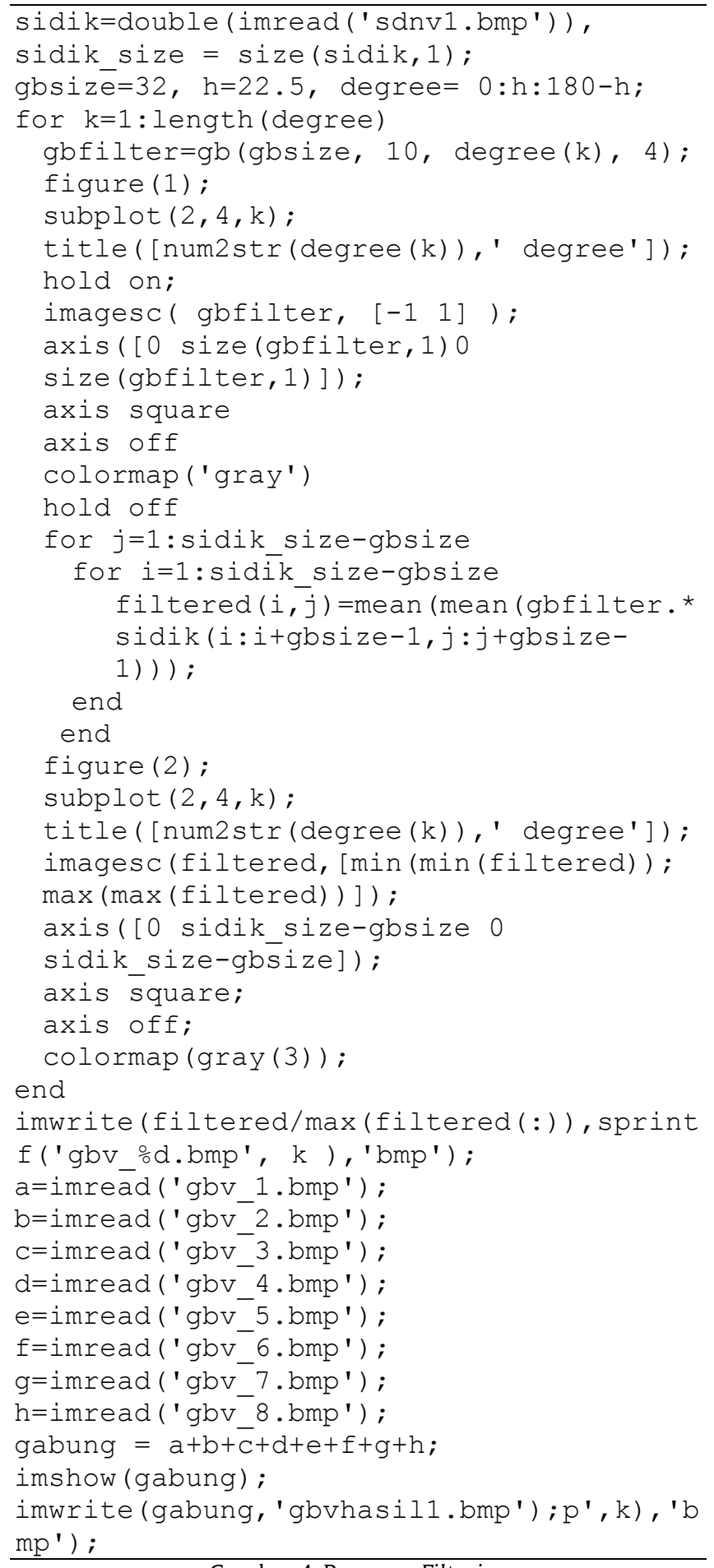

\section{5) Binerisasi}

Proses binerisasi merupakan proses pemisahan piksel-piksel berdasarkan derajat keabuan yang dimilikinya [11]. Piksel yang memiliki derajat keabuan lebih kecil dari nilai batas ditentukan akan diberikan nilai 0 , sementara piksel yang memiliki derajat keabuan yang lebih dari akan diubah menjadi bernilai 1 [12]. Pada penelitian ini dilakukan dengan memakai nilai threshold dengan tujuan untuk melihat mana yang terbaik dalam proses binerisasi. Nilai threshold yang di pilih antara lain 120, 150 dan 180. Tahapan-tahapan proses binerisasi dapat dilihat pada program berikut ini:

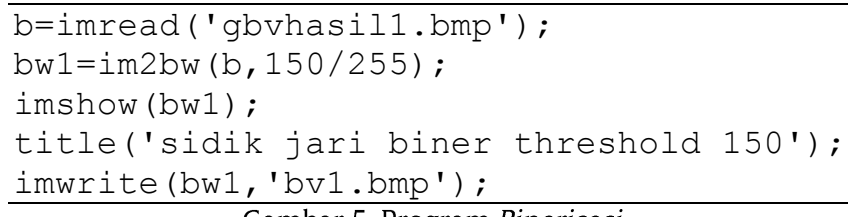

\section{6) Thinning}

Pada proses thinning citra sidik jari didasarkan citra sidik jari biner dan kulitas citra sidik jari biner memiliki pengaruh signifikan terhadap citra sidik jari yang ditipiskan. Algoritma thinning dalam penelitian ini didasarkan pada transformasi hit-miss yang bertujuan untuk menghitung struktur seri. Proses ini akan mengurangi ketetanggaan piksel namu tetap mempertahankan struktur ridge akan membentuk bagian penulangan (skeleton). Penulangan (skeleton) citra sidik jari kemudian digunakan dalam ekstraksi minutiae. Tahapantahapan proses Thinning dapat dilihat pada program berikut ini:

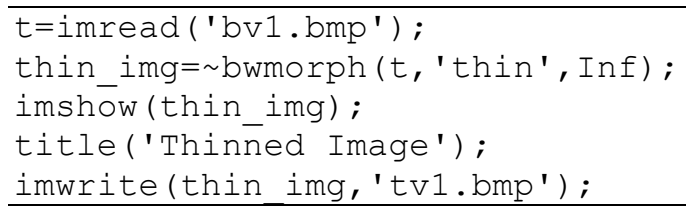

Gambar 6. Program Thinning

\section{7) Minutiae Extraction}

Proses minutiae extraction berfungsi untuk menentukan vector rigde ending (termination) dan bifurcation citra sidik jari. Pada penelitian ini minutiae extraction dilakukan terhadap citra sidik jari asli dan citra sidik jari filter. Tahapan-tahapan proses dapat dilihat pada program berikut ini:

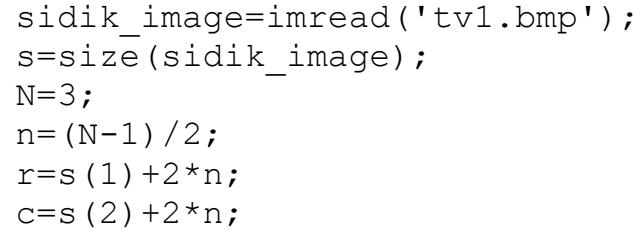




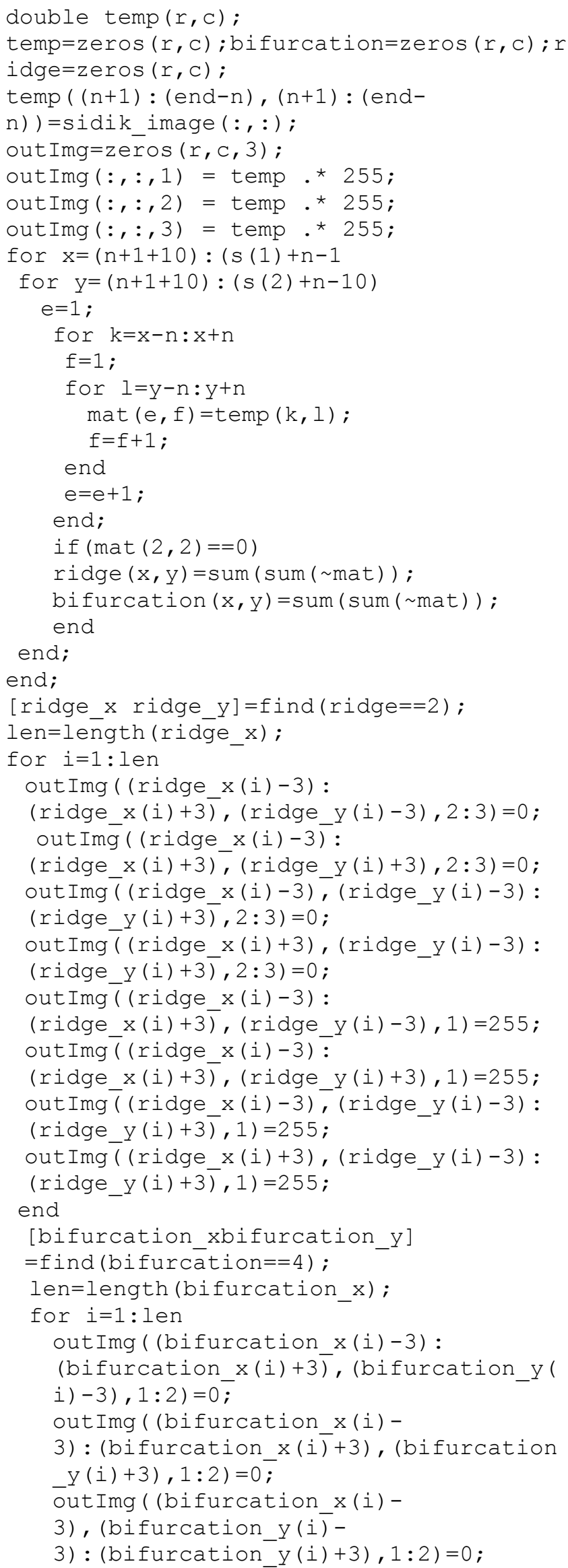

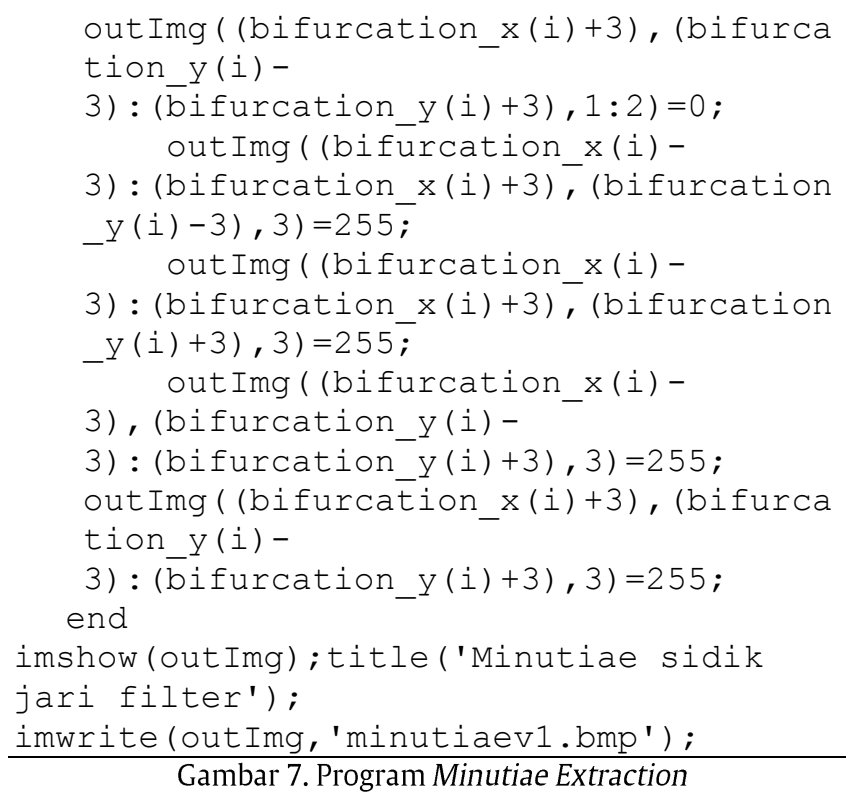

\section{8) Learning Vector Quantization}

Pengujian yang dilakukan adalah dengan metode Learning Vector Quantization didukung dengan software Matalab R2015a. Langkahnya adalah dengan membuat inisialisasi jaringan, namun sebelumnya data yang akan diujikan dibagi menjadi dua bagian, dimana bagian pertama adalah untuk data pelatihan dan bagian kedua adalah untuk data pengujian.

\section{HASIL DAN PEMBAHASAN}

Setiap langkah dari proses yang dilakukan berdasarkan metodologi penelitian, menghasilkan output yang berbeda-beda untuk dapat mencapai tujuan dalam meningkatkan kualitas citra sidik jari.

\section{1) Proses Scanning}

Proses scanning citra sidik jari menggunakan mesin fingerprint HS-52 dengan memberikan tinta pada ibu jari. Scanning citra sidik jari menghasilkan ukuran 256x256 piksel grayscale dalam format bitmap.

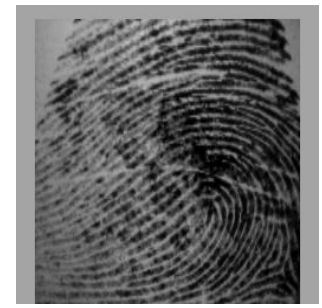

Gambar 8. Hasil Scanning Citra

\section{2) Proses Cropping}

Pada Gambar 9 terdapat bagian citra sidik jari yang tidak diperlukan untuk itu dilakukan proses cropping. Proses cropping menggunakan perintah matlab dengan ukuran potong 20x20 piksel dan 
dilakukan histogram citra sidik jari cropping untuk melihat nilai intensitas.

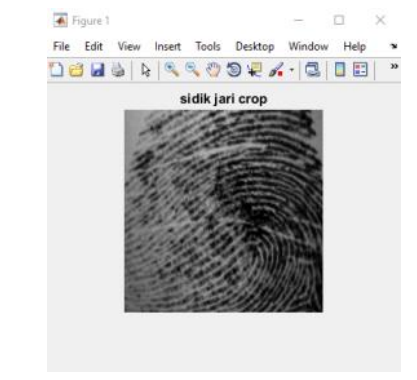

Gambar 9. Hasil Cropping Citra

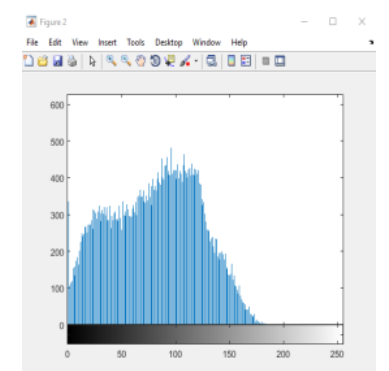

Gambar 10. Histogram Citra Hasil Cropping

\section{3) Proses Normalisasi}

Pada proses cropping histogramnya nilai intensitas menumpuk pada bagian kiri untuk itu dilakukan proses normalisasi. Proses normalisasi menggunakan histogram equalization untuk meratakan nilai intensitas.

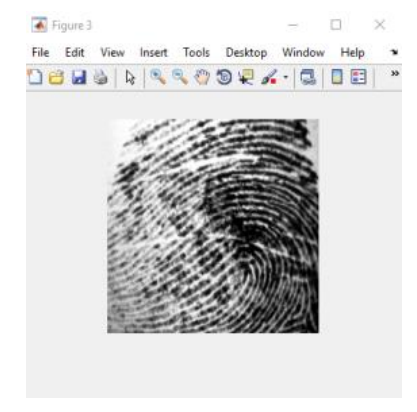

Gambar 11. Hasil Normalisasi Citra

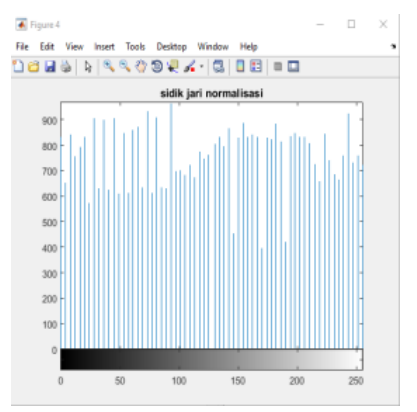

Gambar 12. Histogram Normalisasi Citra

\section{4) Proses Filtering dan Binerisasi}

Pada tahap ini citra sudah ternormalisasi dilakukan proses gabor filter untuk menghasilkan 8 citra sidik jari. Proses filter gabor menggunakan 8 arah orientasi yang berbeda. Selanjutnya citra digabung dan dilakukan proses binerisasi.

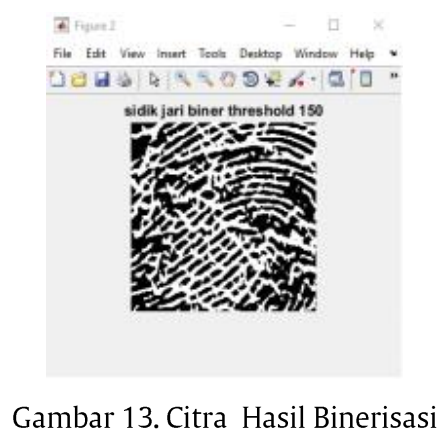

\section{5) Proses Thinning}

Pada tahap ini, berdasarkan hasil binerisasi dilakukan proses thinning untuk menipiskan citra, sehingga nantinya citra yang dihasilkan dapat diproses baik pada tahap minutiae extraction. Proses ini mengurangi ketetanggaan piksel namum tetap mempertahankan kesinambungan antar piksel.

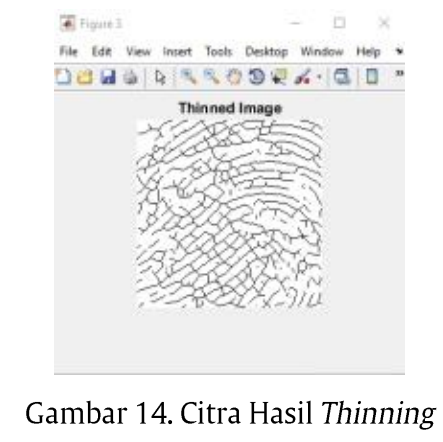

\section{6) Proses Minutiae Extraction}

Pada tahap ini hasil citra thinning dilakukan proses minutae extraction untuk melihat rigde ending (termination) dan bifurcation.

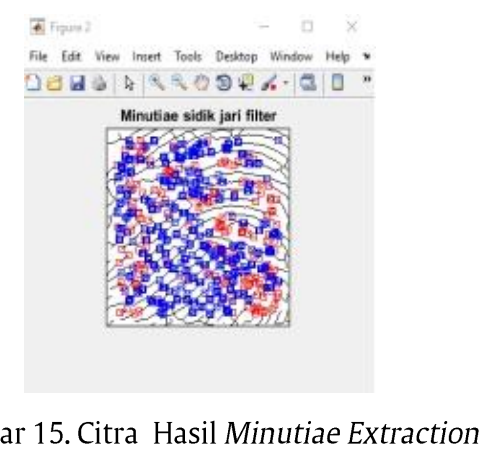

Citra sidik jari pada Gambar 15. merupakan hasil proses minutae extraction, kotak berwarna merah menujukan rigde ending dan kotak berwarna biru bifurcation. 


\section{Pengujian}

Pengujian merupakan tahap yang dilakukan untuk menunjukkan bahwa setiap proses yang telah diimplementasikan dapat berjalan dengan baik dan mampu memberikan hasil yang diinginkan. Tujuan dari pengujian ini adalah untuk menentukan akurasi antar sidik jari sebelum diproses dan setelah diproses. Hasil pengujian dengan Learning Vector Quantization :

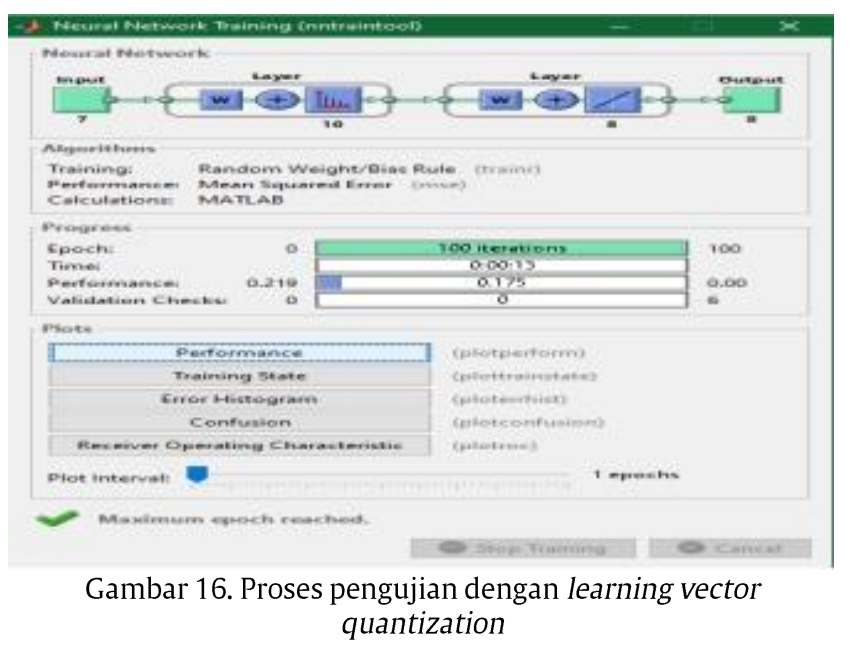

Pada Gambar 16, menjelaskan proses pelatihan data menggunakan Learning Vecktor Quantization eposh nya 100 , hidden layer 10 dan memiliki 8 data keluar. Pada pengujian data dilakukan sebanyak empat jenis pengujian dengan menggunakan data uji sebanyak 25 data, 50 data , 75 data, dan 100 data berdasarkan input dari citra sidik jari sebelum diproses dan sesudah diproses. Hasil akurasi bisa dilihat pada Tabel 1:

\begin{tabular}{clc}
\multicolumn{3}{l}{ Tabel 1. Hasil learning vector quantization } \\
\hline Data citra & \multicolumn{1}{c}{ Input } & Akurasi \% \\
\multirow{2}{*}{25} & Sebelum diproses & 69.00 \\
& Setelah diproses & 79.00 \\
\hline \multirow{2}{*}{50} & Sebelum diproses & 71.00 \\
& Setelah diproses & 85.00 \\
\hline \multirow{2}{*}{75} & Sebelum diproses & 73.34 \\
& Setelah diproses & 83.34 \\
\hline \multirow{2}{*}{100} & Sebelum diporses & 67.00 \\
& Setelah diproses & 82.00 \\
\hline
\end{tabular}

\section{KESIMPULAN}

Dari hasil penelitian untuk peningkatan kualitas citra sidik jari dengan Algoritma Minutiae Extraction dan pengujian dengan Learning Vector Quantization menghasilkan pengenalan sidik jari yang terbaik dengan pengolahan 75 data sidik jari, dengan tingkat akurasi sebesar $83.34 \%$.

\section{DAFTAR PUSTAKA}

[1] S. Guglani and E.P.S. Bhullar, " A New False Minutia Removal Based Fingerprint Identification Technique" , International Journal of Advanced Research in Computer Science (IJARCS), vol. 6, no. 6, pp. 17-19, 2015.

[2] N. Yanti, F.Z. Rachman, N. Jamal, E. Purwanto, Fachrurozy, " Jaringan Syaraf Tiruan Untuk Pengenalan Citra Sidik Jari Pada Smart" , Jurnal Teknologi Informasi dan Ilmu Komputer (JTIIK), vol 5, no. 5, pp. 597-604, 2018.

[3] R. Bansal, P. Sehgal and P. Bedi. " Minutiae Extraction from fingerprint Image : a Review" . International Journal of Computer Science (IJCSI), vol. 5, no. 3, pp. 74-85, 2011.

[4] J. Yang, L. Liu, T. Jiang and Y. Fan, 2003. “ A Modified Gabor Filter Design Method For Fingerprint Image Enhancement" , Pattern Recognition Letters, vol. 24, no. 12, pp. 18051817, 2003.

[5] S. Chavan, P. Mundada and D. Pal, "Fingerprint Authentication Using Gabor Filter Based Matching Algorithm" , International Conference on Technologies for Sustainable Development (ICTSD), Mumbai, India. Feb 04-06, 2015.

[6] N. Kahraman, Z.G.C. Taskiran and M. Taskiran, " Novel Feature Extraction Methodology with Evaluation in Artificial Neural Networks Based Fingerprint Recognition System" , Original scientific paper, vol. 1, no. 1, pp. 112-119, 2018.

[7] L. Weclaw, “ A Minuatiae-Based Matching Algorithms In Fingerprint Recognition Systems" . Journal of Medical Informatics \& Technologies, vol. 13 no.1, pp. 65-71, 2009.

[8] E. Afriandi E and Sutikno. "Identifikasi Telapak Tangan Menggunakan Jaringan Syaraf Tiruan Learning Vector Quantization (LVQ)" , Jurnal Informatics Telecomunication and Eletronics (Infotel), vol. 8, no. 2, pp 107-114, 2018.

[9] J. Santony and J. Na`am , " Infiltrate Object Extraction in X-ray Image by using MathMorphology" , International Journal on Advanced Science, Engineering and Information Technology (IJASEIT), vol. 6, no. 2, pp 239-244, 2016. 
[10] J. Na`am, J. Santony, Yuhandri, Sumijan and G.W. Nurchayo , " Enlarge Medical Image using Line-Column Interpolation (LCI) Method" , International Journal of Electrical and Computer Engineering (IJECE), vol. 8, no.5, pp. 3620-3626, 2018.

[11] R. Wahyudi, O. Soesanto, Muliadi, “ Rancang Bangun Aplikasi Pengenalan Pola Sidik Jari” , Kumpulan jurnaL Ilmu Komputer(KLIK), vol. 2 no.1, pp. 74-83, 2015.

[12] I.R. Wijaya, U.N. Wisesty, S.A. Faraby, "Analisis dan Implementasi Metode Gabor Filter dan Support Vector Machine pada Klasifikasi Sidik Jari" , Indonesian Journal of Computing (Indo-JC), vol. 2, no.2, pp. 37-46, 2017. 